\title{
Analisis Kesehatan Koperasi Kredit Sentosa Palembang
}

\author{
Agustinus Supriyanto \\ Universitas Sumatera Selatan \\ Email: agnsupriyanto@uss.ac.id \\ Rikkie Dekas \\ Universitas Sumatera Selatan \\ Email: rikkie.dekas@gmail.com \\ Ita \\ Universitas Sumatera Selatan \\ Email: Ita.ismail@uss.ac.id
}

\begin{abstract}
The Sentosa Credit Union (CU) is the primary cooperative that runs a savings and loan business and is guided by Government Regulation number 9 of 1995 concerning the implementation of savings and loan business activities. The author conducted research to determine the suitability of financial reports based on the Regulation of the Deputy for Supervision of the Ministry of Cooperatives and Small and Medium Enterprises of the Republic of Indonesia number 06 / Per / Dep.6 / IV / 2016 regarding the assessment of the Health of Savings and Loans Cooperatives and Savings and Loan Units. This type of research is descriptive evaluative research. The data source used is primary dataThe results showed that the health level of Koperasi kredit Sentosa from 2017 - 2019 in the fairly healthy category, on average, got a score of 67.35 with details (1) the aspect of capital on average got a score of 13.80 in the healthy category; (2) the quality aspects of earning assets on average score 14.92 are in the fairly healthy category; (3) management aspects on average score 13.30 are in the healthy category; (4) the efficiency aspect averaged a score of 7.00 in the fairly healthy category; (5) the liquidity aspect scores on average 9.58 and is in the fairly healthy category; (6) aspects of independence and growth on average score 1.75 and are in the fairly healthy category; (7) the aspect of cooperative identity on average gets a score of 7.00 and is in the fairly healthy category
\end{abstract}

Keywords: Level of health, Credit Cooperatives Performance

\begin{abstract}
Abstrak
Koperasi Kredit (Koperasi kredit) merupakan primer koperasi yang menjalankan usaha simpan pinjam dan berpedoman pada Peraturan Pemerintah nomor 9 tahun 1995 tentang pelaksanaan kegiatan usaha simpan pinjam. Penulis melakukan penelitian untuk mengetahui kesesuaian laporan keuangan yang berpedoman pada Peraturan Deputi Bidang Kepengawasan Kementerian Koperasi dan Usaha Kecil dan Menengah Republik Indonesia dengan nomor 06/Per/Dep.6/IV/2016 mengenai penilaian Kesehatan Koperasi Simpan Pinjam dan Unit Simpan Pinjam. Jenis penelitian ini adalah penelitian desktriptif evaluatif. Sumber data yang digunakan adalah data primer yang diterima langsung dari sumbernya. Hasil penelitian menunjukkan bahwa tingkat kesehatan Koperasi kredit Sentosa dari tahun 2017 - 2019 kategori cukup sehat secara rerata mendapatkan skor 67,35 dengan rincian (1) aspek permodalan secara rerata mendapat skor 13,80 berada pada kategori sehat; (2) aspek kualitas aktiva produktif secara rerata mendapat skor 14,92 berada dalam kategori cukup sehat; (3) aspek manajemen secara rerata mendapat skor 13,30 berada dalam kategori sehat; (4) aspek efisiensi secara rerata mendapat skor 7,00 berada dalam kategori cukup sehat; (5) aspek likuiditas secara rerata mendapat skor 9,58 dan berada dalam kategori cukup sehat; (6) aspek kemandirian dan pertumbuhan secara rerata mendapat skor 1,75 dan berada dalam kategori cukup sehat; (7) aspek jati diri koperasi secara rerata mendapat skor 7,00 dan berada dalam kategori cukup sehat
\end{abstract}

Kata Kunci: Tingkat kesehatan, Kinerja Koperasi kredit 


\section{Pendahuluan}

Koperasi adalah badan usaha (Pasal 1 Undang-Undang Nomor 25 tahun 1992) tentang perkoperasian. Sebagai badan usaha koperasi tetap tunduk terhadap kaidah perusahaan dan prinsip - prinsip ekonomi yang berlaku. Perbedaan koperasi dengan badan usaha lainnya adalah posisi anggota, dalam Undang-Undang nomor 25 tahun 1992 anggota koperasi adalah pemilik dan pengguna jasa dalam teori ekonomi disebut pelanggan.

Koperasi kredit Sentosa adalah Koperasi Simpan Pinjam berkedudukan di Jalan Jalan Kamboja No. 1360 Palembang, memberikan pelayanan khusus kepada anggota dan tidak memberikan pelayanan khusus kepada anggota dan tidak memberikan pelayanan kepada non anggota, tercatat sampai tahun 2019 adalah 1.487 orang dengan total aset Rp 7.114.941.330 piutang anggota $\mathrm{Rp}$ 4.869.378.480 dan modal sendiri sebesar Rp 1.727.628.658. Kegiatan usaha Koperasi kredit Sentosa adalah menghimpun dan menyalurkan dana kepada anggota. Pernah terjadi kemacetan yang cukup tinggi, hal ini disebabkan anggota (petani) hampir seratus persen gagal panen, yang mengakibatkan perputaran dana pada tahun 2019 agak tersendat. Pendidikan selalu diberikan secara berkesinambungan. Untuk menghimpun dana Koperasi kredit Sentosa membuka produk pelayanan berjangka, tabungan lebaran dan Tasplus. Pertumbuhan mengalami stabil kenaikan tidak begitu mencolok.

Untuk mengetahui kinerja koperasi maka diperlukan peraturan Deputi Bidang Kepengawasan Kementerian Koperasi dan Usaha Kecil dan Menengah Republik Indonesia Nomor 06/PER/Dep.6/IV/2016 tentang penilaian kesehatan koperasi.

Alasan mendasar Koperasi kredit Sentosa dijadikan untuk penelitian karena memiliki anggota yang cukup heterogen dengan jenis pekerjaan yang berbeda di masyarakat umum, dengan adanya penilaian terhadap kinerja keuangan, pihak yang terkait akan merasa nyaman dan aman bila berurusan dengan koperasi.

Berdasarkan uraian tersebut penulis tertarik untuk meneliti Bagaimana kinerja keuangan Koperasi kredit Sentosa, berdasarkan Peraturan Deputi Bidang Kepengawasan Kementerian Koperasi dan Usaha Kecil dan Menengah Republik Indonesia Nomor 06/PER/Dep.6/IV/2016.

\section{Kajian Pustaka}

\subsection{Pengertian Koperasi}

Menurut Undang-Undang Republik Indonesia No. 25 Tahun 1992 sebagai berikut : Koperasi adalah badan usaha yang beranggotakan orang seorang / badan hukum koperasi dengan melandaskan kegiatannya berdasarkan prinsip koperasi sekaligus sebagai gerakan ekonomi rakyat yang berdasar atas asas kekeluargaan.

Menurut Jochen Ropke (2012: 14) menjelaskan bahwa koperasi adalah suatu organisasi usaha yang para pemilik/anggotanya adalah juga pelanggan utama/klien perusahaan tersebut. Kriteria identitas suatu koperasi merupakan prinsip identitas yang membedakan unit usaha koperasi dari unit usaha lainnya. Prinsip identitas dari suatu koperasi adalah para pemilik dan pengguna jasa dari pelayanan suatu unit usaha adalah orang yang sama.

Pengertian Koperasi Simpan Pinjam menurut Anorga dan Widyawati (2007:192) adalah koperasi yang bergerak dalam lapangan usaha pembentukan modal melalui tabungan-tabungan para anggota secara teratur dan terus menerus dipinjamkan kepada para anggota dengan cara mudah, murah, cepat, dan tepat pada tujuan produktif dan kesejahteraan.

Perangkat Organisasi koperasi menurut Undang-Undang Republik Indonesia No.25 tahun 1992 antara lain : Rapat Anggota, Pengurus, dan Pengawas. 
Penilaian kinerja menurut Utomo, Tri Widodo W (2010). adalah proses untuk mengukur prestasi kerja pegawai berdasarkan peraturan yang telah ditetapkan, dengan cara membandingkan sasaran (hasil kerjanya) dengan persyaratan deskripsi pekerjaan yaitu standar pekerjaan yang telah ditetapkan selama periode tertentu. Standar kerja tersebut dapat dibuat baik secara kualitatif maupun kuantitatif.

\subsection{Laporan Keuangan KSP}

Menurut Ikatan Akuntansi Indonesia (IAI, 2009) dalam ETAP tentang Akuntansi perkoperasian laporan keuangan koperasi meliputi Neraca, Perhitungan Hasil Usaha, Laporan Arus Kas, Laporan Promosi Ekonomi Anggota, dan catatan atas laporan keuangan.

\subsection{Penilaian Kesehatan KSP}

Peraturan Deputi Bidang Kepengawasan Kementerian Koperasi dan Usaha Kecil dan Menengah Republik Indonesia dengan nomor 06/Per/Dep.6/IV/2016 mengenai penilaian Kesehatan Koperasi Simpan Pinjam dan Unit Simpan Pinjam.

Evaluasi dan kinerja dilakukan dengan menilai aspek-aspek dan indikator- indikator yang sudah ditentukan dalam peraturan yang menunjukkan kinerja koperasi. Hasil penilaian kesehatan KSP dan USP Koperasi diklasifikasikan dalam 4 (tiga) kategori, yaitu :

a) sehat, jika hasil penilaian diperoleh total skor $80,00 \leq \mathrm{x}<100$

b) cukup sehat, jika hasil penilaian diperoleh total skor $66,00 \leq \mathrm{x}<80,00$;

c) dalam pengawasan, jika hasil penilaian diperoleh total skor $51,00 \leq x<66,00$; dan

d) dalam pengawasan khusus, jika hasil penilaian diperoleh total skor $0<\mathrm{x}<51,00$.

\subsection{Kerangka Pemikiran}

Gambar 1. Kerangka Pemikiran

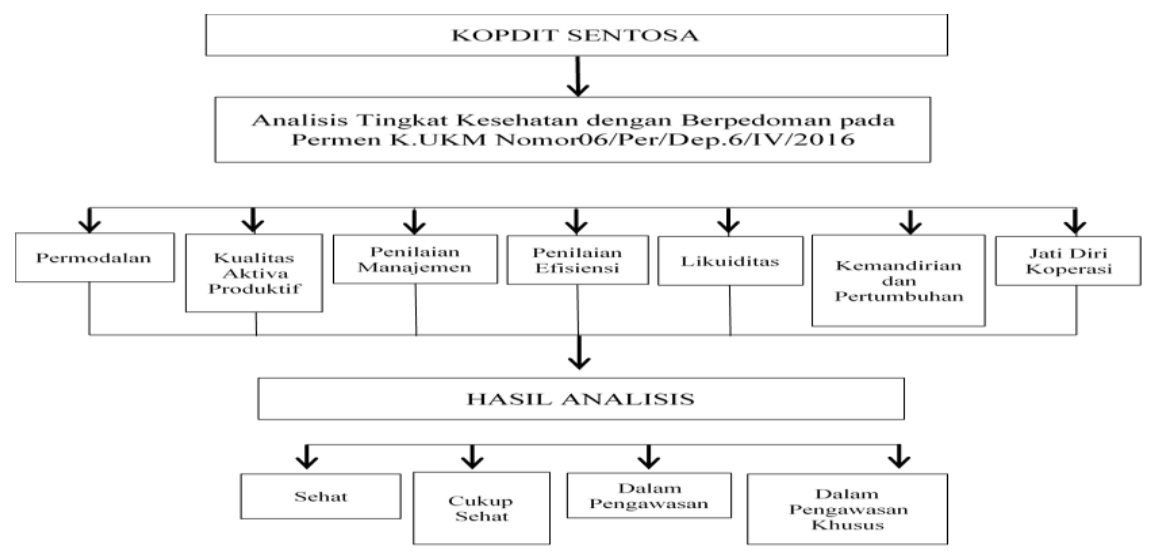

Sumber: Adaptasi, 2020

\section{Metode Penelitian}

Jenis Penelitian ini yaitu penelitian evaluasi dengan pendekatan kuantitatif. Mudrajad Kuncoro (2003: 6) menyatakan bahwa penelitian evaluasi atau evaluation research merupakan penelitian yang diharapkan dapat memberikan masukan/mendukung pengambilan keputusan tentang nilai relatif dari dua atau lebih alternatif tindakan. Sementara itu, Supardi (2005:26) (menyatakan bahwa penelitian evaluasi (evaluation research) merupakan penelitian yang dilakukan untuk merumuskan hasil-hasil pelaksanaan kegiatan yang dilakukan agar diperoleh umpan balik bagi upaya perbaikan perencanaan, sistem dan metode kerja yang telah dilakukan. 
Metode pengumpulan data dengan melakukan observasi untuk mengetahui keadaan koperasi yang sesungguhnya. Selanjutnya melakukan dokumentasi terutama untuk memperoleh data keuangan koperasi, antara lain laporan neraca dan laporan laba rugi atau laporan SHU selama tahun 2016-2018. Kemudian dilengkapi dengan wawancara terstruktur dengan pengurus dan pengelola.

Penelitian ini menggunakan dua jenis data, yaitu : data kualitatif yang berupa perkembangan bisnis, struktur organisasi dan tujuan Koperasi kredit Sentosa. Dan data kuantitatif yang berkaitan dengan jumlah anggota, laporan keuangan (neraca dan perhitungan hasil usaha) laporan promosi anggota Koperasi kredit Sentosa periode 2017 - 2019.

Sumber data primer pada penelitian ini berupa buku laporan pertanggungjawaban pengurus dan pengawas Koperasi kredit Sentosa tahun buku 2017, 2018 dan 2019. Adapun data sekunder diperoleh melalui dokumentasi dan telaah kepustakaan.

Teknik analisis data menggunakan pengujian atributif, dan pengujian subtantif. Pengujian atributif untuk menguji kesesuaian dan kebenaran tentang format dan beberapa komponen yang terdapat dalam laporan keuangan antara lain: neraca, perhitungan hasil usaha dan catatan atas laporan keuangan, khusus KSP menurut Undang-Undang No 25 tahun 1992. Sedangkan kesehatan koperasi simpan pinjam atau unit simpan pinjam diatur dalam Peraturan Deputi Bidang Kepengawasan Kementerian Koperasi dan Usaha Kecil dan Menengah Republik Indonesia Nomor 06/PER/Dep.6/IV/2016 tentang pedoman penilaian kesehatan koperasi. Adapun pengujian subtantif dilakukan untuk menentukan suatu penilaian terhadap kebenaran angkaangka yang terdapatdidalam laporan keuangan.

Objek yang dievaluasi dalam penelitian ini adalah kinerja koperasi dengan menilai tingkat kesehatan koperasi simpan pinjam. Tolok ukur kinerjanya adalah Peraturan Menteri Koperasi dan UMKM Nomor 06/Per/Dep.6/IV/2016. Variabel dalam penelitian ini adalah kinerja Koperasi kredit Sentosa yang merupakan suatu hasil yang dicapai oleh koperasi. Untuk mengukur kinerja koperasi ada 7 aspek yaitu dan dijelaskan sebagai berikut: (1) Permodalan; (2) Kualitas Aktiva Produktif; (3) Manajemen; (4) Penilaian Efisiensi; (5) Likuiditas; (6)Kemandirian dan Pertumbuhan; (7) Jatidiri Koperasi.

Tabel 1. Operasional Variabel

\begin{tabular}{|c|c|c|c|c|}
\hline $\begin{array}{l}\text { Konsep } \\
\text { Variabel }\end{array}$ & $\begin{array}{l}\text { Definisi } \\
\text { Konsep }\end{array}$ & Indikator & Skala Ukur & $\begin{array}{l}\text { Sumber } \\
\text { Data }\end{array}$ \\
\hline \multirow[t]{3}{*}{ Permodalan } & \multirow{3}{*}{$\begin{array}{l}\text { Modal adalah } \\
\text { investasi yang } \\
\text { dilakukan } \\
\text { pemilik } \\
\text { perusahaan. }\end{array}$} & $\begin{array}{l}\text { Perbandingan antara Modal } \\
\text { Sendiri (MS) terhadap Aset. }\end{array}$ & $\begin{array}{l}\text { Rasio MS } \\
\text { Aset } \\
\text { x } 100 \%\end{array}$ & Neraca \\
\hline & & $\begin{array}{l}\text { Perbandingan antara Modal } \\
\text { Sendiri terhadap Pinjaman } \\
\text { yang diberikan berisiko. }\end{array}$ & $\begin{array}{l}\text { Rasio MS } \\
\text { Pinj.Diberikan Brisiko } \\
\text { x } 100 \%\end{array}$ & Neraca \\
\hline & & $\begin{array}{l}\text { Perbandingan antara Modal } \\
\text { Sendiri Tertimbang } \\
\text { (MTMR) terhadap ATMR. }\end{array}$ & $\begin{array}{l}\text { Rasio } \\
\text { MTMR } \\
\text { ATMR } \\
\text { x } 100 \% \\
\end{array}$ & Neraca \\
\hline \multirow[t]{2}{*}{$\begin{array}{l}\text { Kualitas Aktiva } \\
\text { Produktif }\end{array}$} & \multirow[t]{2}{*}{$\begin{array}{l}\text { Adalah } \\
\text { kekayaan yang } \\
\text { menghasilkan } \\
\text { keuntungan } \\
\text { dalam }\end{array}$} & $\begin{array}{l}\text { Perbandingan antara Volume } \\
\text { Pinjaman pada anggota } \\
\text { (VPA) terhadap Volume } \\
\text { Pinjaman (VP) }\end{array}$ & $\begin{array}{l}\begin{array}{l}\text { Rasio } \\
\text { (VPA) }\end{array} \\
\mathrm{VP} \\
\mathrm{x} 100 \% \\
\end{array}$ & Neraca \\
\hline & & Perbandingan antara & Rasio & Neraca \\
\hline
\end{tabular}




\begin{tabular}{|c|c|c|c|c|}
\hline & \multirow[t]{3}{*}{ koperasi } & \multirow{2}{*}{$\begin{array}{l}\text { Pinjaman Bermasalah (PB) } \\
\text { terhadap Pinjaman yang } \\
\text { diberikan (PD) } \\
\text { Perbandingan antara } \\
\text { Cadangan Risiko (DCR) } \\
\text { terhadap Pinjaman } \\
\text { Bermasalah (PB) } \\
\end{array}$} & $\begin{array}{l}\mathrm{PB} \\
\mathrm{PD} \\
\times 100 \%\end{array}$ & \\
\hline & & & $\begin{array}{l}\text { Rasio } \\
\text { DCR } \\
\text { PB } \\
\times 100 \%\end{array}$ & Neraca \\
\hline & & $\begin{array}{l}\text { Perbandingan antara } \\
\text { Pinjaman yang berisiko } \\
\text { (PDB) terhadap Pinjaman } \\
\text { yang Diberikan (PD) }\end{array}$ & $\begin{array}{l}\text { Rasio } \\
\text { PDB } \\
\text { PD } \\
\text { X } 100 \%\end{array}$ & Neraca \\
\hline \multirow[t]{5}{*}{ Manajemen } & $\begin{array}{l}\text { Manajemen } \\
\text { Umum }\end{array}$ & 12 questioner & Wawancara terstruktur & \\
\hline & $\begin{array}{l}\text { Manajemen } \\
\text { Kelembagaan }\end{array}$ & 6 questioner & Wawancara terstruktur & \\
\hline & $\begin{array}{l}\text { Manajemen } \\
\text { Permodalan }\end{array}$ & 5 questioner & Wawancara terstruktur & \\
\hline & $\begin{array}{l}\text { Manajemen } \\
\text { Aktiva }\end{array}$ & 10 questioner & Wawancara terstruktur & \\
\hline & $\begin{array}{l}\text { Manajemen } \\
\text { Likuiditas }\end{array}$ & 5 questioner & Wawancara terstruktur & \\
\hline \multirow[t]{3}{*}{ Efisiensi } & \multirow{3}{*}{$\begin{array}{l}\text { Penilaian } \\
\text { efisiensi } \\
\text { memberikan } \\
\text { penilaian } \\
\text { seberapa besar } \\
\text { koperasi } \\
\text { mampu } \\
\text { memberikan } \\
\text { pelayanan } \\
\text { kepada } \\
\text { anggota }\end{array}$} & $\begin{array}{l}\text { Perbandingan antara Beban } \\
\text { Operasi Anggota (BOA) } \\
\text { terhadap Partisipasi Bruto } \\
\text { (PB) }\end{array}$ & $\begin{array}{l}\text { Rasio } \\
\text { BOA } \\
\text { PB } \\
\mathrm{x} 100 \%\end{array}$ & Neraca \\
\hline & & $\begin{array}{l}\text { Perbandingan antara Beban } \\
\text { Usaha terhadap SHU Kotor }\end{array}$ & $\begin{array}{l}\text { Rasio BU } \\
\text { SHU Kotor } \\
\text { x } 100 \%\end{array}$ & Neraca \\
\hline & & $\begin{array}{l}\text { Perbandingan antara Beban } \\
\text { Karyawan (BK) terhadap } \\
\text { Volume Pinjaman (VP) }\end{array}$ & $\begin{array}{l}\text { Rasio } \\
\text { BK } \\
\text { VP } \\
\text { x } 100 \%\end{array}$ & Neraca \\
\hline \multirow[t]{2}{*}{ Likuiditas } & \multirow{2}{*}{$\begin{array}{l}\text { Adalah } \\
\text { kemampuan } \\
\text { koperasi } \\
\text { dalam } \\
\text { memenuhi } \\
\text { kewajiban } \\
\text { jangka pendek }\end{array}$} & $\begin{array}{l}\text { Perbandingan antara } \\
\text { Kas+Bank terhadap } \\
\text { Kewajiban Lancar }\end{array}$ & $\begin{array}{l}\text { Rasio } \\
\text { Kas + Bank } \\
\text { Kewajiban Lancar } \\
\text { x 100\% } \\
\end{array}$ & Neraca \\
\hline & & $\begin{array}{l}\text { Perbandingan antara } \\
\text { Pinjaman Diberikan } \\
\text { terhadap Dana Diterima }\end{array}$ & $\begin{array}{l}\text { Rasio Pinj. Diberikan } \\
\text { Dana yg Diterima } \\
\text { x } 100 \%\end{array}$ & Neraca \\
\hline \multirow[t]{3}{*}{$\begin{array}{l}\text { Kemandirian } \\
\text { dan } \\
\text { Pertumbuhan }\end{array}$} & \multirow{3}{*}{$\begin{array}{l}\text { Menggambark } \\
\text { an kualitas } \\
\text { dari aset yang } \\
\text { dimiliki dalam } \\
\text { menghasilkan } \\
\text { laba. }\end{array}$} & $\begin{array}{l}\text { Perbandingan antara SHU } \\
\text { sebelum Pajak terhadap } \\
\text { Total Aset }\end{array}$ & $\begin{array}{l}\text { Rasio SHU Sblm Pjk } \\
\text { Total Aset } \\
\text { x } 100 \%\end{array}$ & Neraca \\
\hline & & $\begin{array}{l}\text { Perbandingan antara SHU } \\
\text { Bagian Anggota terhadap } \\
\text { Total Modal Sendiri }\end{array}$ & $\begin{array}{l}\text { Rasio } \\
\text { SHU bagian Anggota } \\
\text { Total Modal Sendiri } \\
\mathrm{x} 100 \%\end{array}$ & Neraca \\
\hline & & $\begin{array}{l}\text { Perbandingan antara } \\
\text { Partisipasi Bruto terhadap } \\
\text { Beban Usaha+Beban } \\
\text { Perkoperasian }\end{array}$ & $\begin{array}{l}\text { Rasio } \\
\text { Partisipasi Bruto } \\
\text { Beban Usaha + Beban } \\
\text { Perkoperasian } \\
\text { x 100\% }\end{array}$ & Neraca \\
\hline
\end{tabular}




\begin{tabular}{|c|c|c|c|c|}
\hline $\begin{array}{l}\text { Jati Diri } \\
\text { Koperasi }\end{array}$ & $\begin{array}{l}\text { Untuk } \\
\text { mengukur } \\
\text { keberhasilan } \\
\text { koperasi } \\
\text { mencapai tu - } \\
\text { juannya yaitu } \\
\text { promosi ekono } \\
\text { mi anggota. }\end{array}$ & $\begin{array}{l}\text { Perbandingan antara } \\
\text { Partisipasi Bruto terhadap } \\
\text { Partisipasi Bruto }+ \\
\text { Pendapatan }\end{array}$ & $\begin{array}{l}\text { Rasio } \\
\text { Partisipasi Bruto } \\
\text { Partisipasi } \\
\text { Bruto+Pendapatan } \\
\text { x 100\% }\end{array}$ & Neraca \\
\hline & & $\begin{array}{l}\text { Perbandingan antara } \\
\text { Promosi Ekonomi Anggota } \\
\text { (PEA) terhadap SP+SW }\end{array}$ & $\begin{array}{l}\text { Rasio } \\
\text { PEA } \\
\text { SP + SW } \\
\times 100 \%\end{array}$ & Neraca \\
\hline
\end{tabular}

Sumber : Peraturan Menteri Koperasi dan UMKM Nomor 06/Per/Dep.6/IV/2016

\section{Hasil dan Pembahasan}

Analisis data yang digunakan dalam penelitian ini menggunakan analisis deskriptif dengan berpedoman pada Peraturan Deputi Bidang Pengawasan Kementerian Koperasi dan UKM Nomor 06/Per/Dep.6/IV/2016. Aspek yang dinilai yaitu :

1) Aspek Permodalan

Tabel 2. Penilaian Rasio Permodalan

\begin{tabular}{|c|c|c|c|c|c|c|c|}
\hline \multirow{2}{*}{ No } & \multirow{2}{*}{ Aspek Penilaian } & \multicolumn{2}{|c|}{ Tahun 2019} & \multicolumn{2}{|c|}{ Tahun 2018} & \multicolumn{2}{|c|}{ Tahun 2017} \\
\hline & & Rasio & Skor & Rasio & Skor & Rasio & Skor \\
\hline \multirow[t]{5}{*}{$\mathrm{I}$} & PERMODALAN & \multicolumn{2}{|c|}{12,00} & \multicolumn{2}{|c|}{12,00} & \multicolumn{2}{|c|}{12,00} \\
\hline & $\begin{array}{ll}\text { 1. } & \text { Ekuitas terhadap Total } \\
\text { Aset }\end{array}$ & 24,73 & 3,00 & 24,61 & 3,00 & 21,17 & 3,00 \\
\hline & $\begin{array}{l}\text { 2. } \begin{array}{l}\text { Modal Sendiri terhadap } \\
\text { Pinjaman diberikan } \\
\text { yang berisiko }\end{array} \\
\end{array}$ & 570,28 & 6,00 & 635,44 & 6,00 & 388,96 & 6,00 \\
\hline & 3. Kecukupan Modal & 70,32 & 3,00 & 69,29 & 3,00 & 71,79 & 3,00 \\
\hline & Predikat & \multicolumn{2}{|c|}{ Sehat } & \multicolumn{2}{|c|}{ Sehat } & \multicolumn{2}{|c|}{ Sehat } \\
\hline
\end{tabular}

Sumber: Data Primer yang Diolah, 2017 - 2019

Berdasarkan tabel 2 dapat diketahui peningkatan dan penurunan rasio permodalan sebagai berikut :

1. Rasio modal sendiri terhadap total aset selama tiga tahun mengalami kenaikan, walaupun tidak mempengaruhi skor. Ideal rasionya $40-60 \%$. Modal sendiri perlu ditingkatkan.

2. Modal Sendiri terhadap Pinjaman diberikan yang berisiko selama tiga tahun tidak mengalami perubahan dan rasionya diatas $100 \%$, sudah sangat baik dan memperoleh skor 6

3. Kecukupan Modal Sendiri selama tiga tahun tidak mengalami perubahan dan rasionya diatas $8 \%$ sudah sangat baik dan memperoleh skor 3

4. Secara keseluruhan aspek permodalan dirata - ratakan memperoleh predikat Sehat

2) Aspek Kualitas Aktiva produktif

Tabel 3. Penilaian Kualitas Aktiva Produktif

\begin{tabular}{|l|l|l|l|l|}
\hline No & Aspek Penilaian & Tahun 2019 & Tahun 2018 & Tahun 2017 \\
\hline
\end{tabular}




\begin{tabular}{|c|c|c|c|c|c|c|c|}
\hline \multirow[b]{2}{*}{ II } & & Rasio & Skor & Rasio & Skor & Rasio & Skor \\
\hline & $\begin{array}{l}\text { KUALITAS AKTIVA } \\
\text { PRODUKTIF }\end{array}$ & \multicolumn{2}{|c|}{19,50} & \multicolumn{2}{|c|}{19,50} & \multicolumn{2}{|c|}{19,50} \\
\hline & $\begin{array}{l}\text { 1) Pinjaman pd Anggota } \\
\text { terhadap Total } \\
\text { Piutang }\end{array}$ & 100,00 & 10,00 & 100,00 & 10,00 & 100,00 & 10,00 \\
\hline & $\begin{array}{l}\text { 2) Pinjaman Bermasalah } \\
\text { Thdp Total Piutang }\end{array}$ & 4,75 & 4,00 & 5,57 & 4,00 & 7,19 & 4,00 \\
\hline & $\begin{array}{l}\text { 3) Cad. Risiko Thdp } \\
\text { Pinjaman Bermasalah }\end{array}$ & 10,03 & 0,50 & 7,58 & 0,50 & 3,22 & 0,50 \\
\hline & $\begin{array}{l}\text { 4) Pinjaman berisiko } \\
\text { thdp pinjaman yg } \\
\text { diberikan }\end{array}$ & 4,12 & 5,00 & 5,27 & 5,00 & 7,22 & 5,00 \\
\hline & Predikat & \multicolumn{2}{|c|}{ Sehat } & \multicolumn{2}{|c|}{ Sehat } & \multicolumn{2}{|c|}{ Sehat } \\
\hline
\end{tabular}

Sumber data: Data Primer yang Diolah, 2017 - 2019

1. Pinjaman pada anggota terhadap total piutang selama tiga tahun stabil, karena pelayanan dilakukan hanya untuk anggota dan tidak memberikan pelayanan kepada non anggota, maka rasio tersebut $100 \%$ dan memperoleh skor 10,00

2. Pinjaman bermasalah terhadap total piutang selama tiga tahun mengalami penurunan dari tahun 2017,2018 dan 2019 yaitu 7,19\%, 5,57 dan 4,75 cukup baik bila perlu diturunkan kembali dibawah 4,75\% . pada analisa rasio ini masih ideal.

3. Cadangan risiko terhadap pinjaman bermasalah selama tiga tahun mengalami kenaikan dari tahun 2017,2018 dan 2019 yaitu 3,22\%, 7,58 dan 10,3 bila dibandingkan dengagn pinjaman bermasalah rasionya masih rendah.

4. Pinjaman berisiko terhadap pinjaman yang diberikan selama tiga tahun mengalami penurunan dari tahun 2017, 2018 dan 2019 yaitu7,22\%, 5,27 dan 4,12. Hal tersebut cukup baik karena rasio idealnya dibawah $21 \%$

5. Secara keseluruhan aspek kualitas aktiva produktif dirata-ratakan memperoleh predikat Sehat

3) Aspek Manajemen

Tabel 4. Penilaian Manajemen

\begin{tabular}{|c|c|c|c|c|c|c|c|}
\hline \multirow{2}{*}{ No } & \multirow{2}{*}{ Aspek Penilaian } & \multicolumn{2}{|c|}{ Tahun 2019} & \multicolumn{2}{|c|}{ Tahun 2018} & \multicolumn{2}{|c|}{ Tahun 2017} \\
\hline & & Rasio & Skor & Rasio & Skor & Rasio & Skor \\
\hline III & MANAJEMEN & \multicolumn{2}{|c|}{15,00} & \multicolumn{2}{|c|}{15,00} & \multicolumn{2}{|c|}{15,00} \\
\hline & 1) Manajemen Umum & 12,00 & 3,00 & 12,00 & 3,00 & 12,00 & 3,00 \\
\hline & $\begin{array}{l}\text { 2) Manajemen } \\
\text { Kelembagaan }\end{array}$ & 6,00 & 3,00 & 6,00 & 3,00 & 6,00 & 3,00 \\
\hline & $\begin{array}{l}\text { 3) Manajemen } \\
\text { Permodalan }\end{array}$ & 5,00 & 3,00 & 5,00 & 3,00 & 5,00 & 3,00 \\
\hline & 4) Manajemen Aset & 10,00 & 3,00 & 10,00 & 3,00 & 10,00 & 3,00 \\
\hline & $\begin{array}{l}\text { 5) } \text { Manajemen } \\
\text { Likuiditas }\end{array}$ & 5,00 & 3,00 & 5,00 & 3,00 & 5,00 & 3,00 \\
\hline & 6) Predikat & \multicolumn{2}{|c|}{ Sehat } & \multicolumn{2}{|c|}{ Sehat } & \multicolumn{2}{|c|}{ Sehat } \\
\hline
\end{tabular}

Sumber data: Data Primer yang Diolah, 2017 - 2019

Pada aspek manajemen yang terdiri dari manajemen umum, manajemen kelembagaan, manajemen permodalan, manajemen aset dan manajemen likuiditas, dari tahun 2017, 2018 dan 2019 memiliki skor rata- rata 3 dengan predikat sehat. Skor tersebut diperoleh dari data 
primer yang tersedia dan hasil wawancara penulis dengan pengurus dan manajemen Koperasi kredit Sentosa.

4) Aspek Efisien

Tabel 5. Penilaian Efisiensi

\begin{tabular}{|c|l|c|c|c|c|c|c|}
\hline \multirow{2}{*}{ No } & \multicolumn{2}{|c|}{ Aspek Penilaian } & \multicolumn{2}{c|}{ Tahun 2019 } & \multicolumn{2}{c|}{ Tahun 2018 } & \multicolumn{2}{c|}{ Tahun 2017 } \\
\cline { 3 - 8 } & \multicolumn{2}{|c|}{ Rasio } & Skor & Rasio & Skor & Rasio & Skor \\
\hline IV & EFISIENSI & \multicolumn{2}{|c|}{$\mathbf{8 , 0 0}$} & \multicolumn{2}{|c|}{$\mathbf{7 , 0 0}$} & \multicolumn{2}{c|}{$\mathbf{6 , 0 0}$} \\
\hline $\begin{array}{l}\text { 1. Beban.operasion thdp } \\
\text { partisipasi bruto }\end{array}$ & 93,94 & 3,00 & 97,20 & 2,00 & 100,47 & 1,00 \\
\hline $\begin{array}{l}\text { 2. Beban Usaha terhadap } \\
\text { SHU Kotor }\end{array}$ & 41,63 & 3,00 & 44,64 & 3,00 & 45,69 & 3,00 \\
\hline $\begin{array}{l}\text { 3. Rasio Efisiensi } \\
\text { Pelayanan }\end{array}$ & 1,75 & 2,00 & 1,71 & 2,00 & 1,59 & 2,00 \\
\hline & $\begin{array}{l}\text { Predikat } \\
\text { Sehat }\end{array}$ & \multicolumn{3}{|c|}{ Cukup Sehat } & \multicolumn{2}{c|}{ Cukup Sehat } \\
\hline
\end{tabular}

Sumber data: Data Primer yang Diolah, 2017 - 2019

1. Beban operasi terhadap partisipasi bruto mengalami peningkatan dari tahun 2017, 2018 dan 2019 yaitu 100,47\%, 97,20\% dan 93,94\%. Beban operasi tersebut dapat ditekan dan idealnya dibawah $90 \%$.

2. Beban usaha terhadap SHU kotor idealnya $\leq 40 \%$ selama 3 tahun mengalami penurunan dari tahun 2017, 2018 dan 2019 yaitu 45,69\%, 44,64\% dan 41,63\% sekalipun tidak mempengaruhi skor.

3. Efisiensi pelayanan idealnya $>15 \%$ selama tiga tahun mengalami kenaikan dari tahun 2017, 2018 dan 2019 yaitu 1,59\%, 1,71\% dan 1,75\% dan perlu di tingkatkan lagi.

4. Secara keseluruhan aspek efisiensi tahun 2017 dan 2018 predikat Cukup Sehat dan tahun 2019 predikat Sehat.

5) Aspek Likuiditas

Tabel 6. Penilaian Likuiditas

\begin{tabular}{|c|c|c|c|c|c|c|c|}
\hline \multirow{2}{*}{ No } & \multirow{2}{*}{ Aspek Penilaian } & \multicolumn{2}{|c|}{ Tahun 2019} & \multicolumn{2}{|c|}{ Tahun 2018} & \multicolumn{2}{|c|}{ Tahun 2017} \\
\hline & & Rasio & Skor & Rasio & Skor & Rasio & Skor \\
\hline $\mathrm{V}$ & LIKUIDITAS & \multicolumn{2}{|c|}{13,75} & \multicolumn{2}{|c|}{6,25} & \multicolumn{2}{|c|}{8,75} \\
\hline & $\begin{array}{l}\text { 1. Rasio Kas dan Bank } \\
\text { thdp Kewajiban Lancar }\end{array}$ & 13,42 & 10,00 & 23,53 & 2,50 & 19,68 & 5,00 \\
\hline & $\begin{array}{l}\text { 2. Rasio Pinj. diberikan } \\
\text { thdp Dana yg diterima }\end{array}$ & 77,87 & 3,75 & 73,47 & 3,75 & 75,36 & 3,75 \\
\hline & Predikat & \multicolumn{2}{|c|}{ Sehat } & \multicolumn{2}{|c|}{$\begin{array}{c}\text { Dalam } \\
\text { Pengawasan }\end{array}$} & \multicolumn{2}{|c|}{ Cukup Sehat } \\
\hline
\end{tabular}

Sumber data: Data Primer yang Diolah, 2017 - 2019

1. Rasio kas dan bank terhadap kewajiban lancar idealnya 10 - 15\% dari tahun 2017,2018 dan 2019 yaitu 19,68\%, 23,53\% dan 13,42\%. Tahun 2019 sangat baik bila dibandingkan dengan tahun 2017 dan 2018.

2. Pinjaman yang diberikan terhadap dana yang diterima idealnya $\leq 80-90 \%$ selama 3 tahun mengalami naik turun dari tahun 2017, 2018 dan 2019 yaitu 75,36\%, 73,47\% dan $77,87 \%$ skor mengalami kenaikan.

3. Secara keseluruhan aspek likuiditas tahun 2019 memperoleh predikat Sehat, lebih baik dari pada tahun 2017 dan 2018. 
6) Aspek Kemandirian dan Pertumbuhan

Tabel 7. Penilaian Kemandirian dan Pertumbuhan

\begin{tabular}{|c|c|c|c|c|c|c|c|}
\hline \multirow{2}{*}{ No } & \multirow{2}{*}{ Aspek Penilaian } & \multicolumn{2}{|c|}{ Tahun 2019} & \multicolumn{2}{|c|}{ Tahun 2018} & \multicolumn{2}{|c|}{ Tahun 2017} \\
\hline & & Rasio & Skor & Rasio & Skor & Rasio & Skor \\
\hline VI & $\begin{array}{l}\text { KEMANDIRIAN DAN } \\
\text { PERTUMBUHAN }\end{array}$ & \multicolumn{2}{|c|}{5,50} & \multicolumn{2}{|c|}{$\mathbf{5 , 5 0}$} & \multicolumn{2}{|c|}{5,50} \\
\hline & $\begin{array}{l}\text { 1) Rasio Rentabilitas } \\
\text { Aset }\end{array}$ & 1,49 & 0,75 & 1,27 & 0,75 & 1,38 & 0,75 \\
\hline & $\begin{array}{l}\text { 2) Rasio Rentabilitas } \\
\text { Modal Sendiri }\end{array}$ & 2,74 & 0,75 & 2,21 & 0,75 & 2,10 & 0,75 \\
\hline & $\begin{array}{l}\text { 3) Rasio Kemandirian } \\
\text { Operasional } \\
\text { Pelayanan }\end{array}$ & 111,66 & 4,00 & 107,57 & 4,00 & 107,79 & 4,00 \\
\hline & Predikat & \multicolumn{2}{|c|}{ Cukup Sehat } & \multicolumn{2}{|c|}{ Cukup Sehat } & \multicolumn{2}{|c|}{ Cukup Sehat } \\
\hline
\end{tabular}

Sumber data: Data Primer yang Diolah, 2017 - 2019

1. Rentabilitas aset selama tiga tahun tidak mengalami mengalami perubahan dari tahun 2017, 2018 dan 2019 yaitu 1,38\%, 1,27\% dan 1,49\%. Ideal rasio rentabilitas aset diatas $10 \%(\geq 10 \%)$

2. Rentabilitas modal sendiri selama tiga tahun tidak mengalami mengalami perubahan dari tahun 2017, 2018 dan 2019 yaitu 2,10\%, 2,21\% dan 2,74\%. Ideal rasio rentabilitas modal sendiri diatas $5 \%(\geq 5 \%)$

3. Kemandirian operasional pelayanan selama tiga tahun tidak mengalami mengalami perubahan dari tahun 2017, 2018 dan 2019 yaitu 107,79\%, 107,57\% dan 111,66\%. Rasio tersebut cukup baik dan perlu dipertahankan. Ideal rasio rentabilitas modal sendiri diatas $100 \%$ (>100\%).

4. Secara keseluruhan rasio kemandirian dan pertumbuhan memperoleh predikat cukup sehat.

7) Aspek Jatidiri Koperasi

Tabel 8. Penilaian Jatidiri Koperasi

\begin{tabular}{|c|c|c|c|c|c|c|c|}
\hline \multirow{2}{*}{ No } & \multirow{2}{*}{ Aspek Penilaian } & \multicolumn{2}{|c|}{ Tahun 2019} & \multicolumn{2}{|c|}{ Tahun 2018} & \multicolumn{2}{|c|}{ Tahun 2017} \\
\hline & & Rasio & Skor & Rasio & Skor & Rasio & Skor \\
\hline VII & JATI DIRI KOPERASI & \multicolumn{2}{|c|}{7,00} & \multicolumn{2}{|c|}{7,00} & \multicolumn{2}{|c|}{7,00} \\
\hline & 1. Rasio Partisipasi Bruto & 100,00 & 7,00 & 100,00 & 7,00 & 100,00 & 7,00 \\
\hline & $\begin{array}{l}\text { 2. Rasio Promosi } \\
\text { Ekonomi Anggota }\end{array}$ & $(3,07)$ & 0 & $(1,94)$ & 0 & $(0,15)$ & 0 \\
\hline & Predikat & \multicolumn{2}{|c|}{ Cukup Sehat } & \multicolumn{2}{|c|}{ Cukup Sehat } & \multicolumn{2}{|c|}{ Cukup Sehat } \\
\hline
\end{tabular}

Sumber data: Data Primer yang Diolah, 2017 - 2019

1. Partisipasi bruto idealnya $\geq 75 \%$, dari tahun 2017, 2018 dan 2019 memperoleh rasio $100 \%$ dan sangat baik dan perlu dipertahankan.

2. Promosi ekonomi anggota idealnya $\geq 10 \%$ selama 3 tahun memperoleh rasio minus (dibawah nol \%) maka selama tiga tahun memperoleh skor 0.

3. Secara keseluruhan jati diri koperasi memperoleh predikat cukup sehat.

\subsection{Interpretasi hasil}

Hasil penelitian dengan 7 aspek penilaian dalam kurun waktu 3 (tiga) tahun dapat sebagai berikut : 
1. Tahun 2017, Koperasi kredit Sentosa mendapat predikat nilai kesehatan Cukup Sehat, dengan nilai skor $\mathbf{6 7 , 4 0}$

2. Tahun 2018, Koperasi kredit Sentosa mendapat predikat nilai kesehatan Cukup Sehat, dengan nilai skor $\mathbf{6 6 , 2 5}$

3. Tahun 2019, Koperasi kredit Sentosa mendapat predikat nilai kesehatan Cukup Sehat, dengan skor $\mathbf{6 8 , 4 0}$

Skor tertinggi diperoleh pada tahun buku 2019 sebesar 68,40 dan nilai skor tidak mempengaruhi. Rasio modal sendiri terhadap total aset selama tiga tahun tidak mengalami perubahan walaupun tidak mempengaruhi skor. Modal sendiri perlu ditingkatkan untuk mencapai ideal rasio $40-60 \%$

Pinjaman bermasalah terhadap total piutang selama tiga tahun masih tinggi dari tahun 2017, 2018 dan 2019 yaitu 22,88\%, 29,38 dan 27,21 idealnya dibawah 5\%, membutuhkan perhatian khusus. Cadangan risiko terhadap pinjaman bermasalah selama tiga tahun mengalami kenaikan dari tahun 2017,2018 dan 2019 yaitu 37,79\%, 24,09 dan 28,54 bila dibandingkan dengagn pinjaman bermasalah rasionya masih rendah, minimal setara dengan pinjaman bermasalah.

Aspek manajemen yang meliputi manajemen umum, kelembagaan, manajemen permodalan, manajemen aktiva, manajemen likuiditas. Berdasarkan analisa penulis baik dari data keuangan maupun melalui wawancara dengan pengurus dan manajemen Koperasi kredit Sentosa. Semua aspek tersebut sudah terpenuhi sesuai dengan data yang dibutuhkan.

Aspek penilaian efisiensi, salah satu indikator yang perlu diperhatikan yaitu Beban usaha terhadap SHU kotor idealnya $\leq 40 \%$ selama 3 tahun mengalami penurunan dari tahun 2017, 2018 dan 2019 yaitu 12,11\%, 3,44\% dan 5,25\% sekalipun tidak mempengaruhi skor. Beban usaha tersebut harus ditekan minimal $40 \%$ bila dibandingkan dengan SHU kotor.

Pinjaman yang diberikan terhadap dana yang diterima idealnya $\leq 80-90 \%$ selama 3 tahun mengalami naik turun dari tahun 2017, 2018 dan 2019 yaitu 70,97\%, 67,99\% dan 68,44\% skor mengalami kenaikan namun masih di bawah standar ideal. Rentabilitas aset selama tiga tahun mengalami perubahan dari tahun 2017, 2018 dan 2019 yaitu 0,07\%, 0,17\% dan 0,099\%. Ideal rasio rentabilitas aset diatas $10 \%(\geq 10 \%)$. Rentabilitas modal sendiri selama tiga tahun mengalami kenaikan dari tahun 2017, 2018 dan 2019 yaitu 0,07\%, 1,36\% dan 3,16\%. Ideal rasio rentabilitas modal sendiri diatas 5\% ( $\geq 5 \%)$. Promosi ekonomi anggota idealnya $\geq 10 \%$ selama 3 tahun memperoleh rasio minus (dibawah nol \%) maka selama tiga tahun memperoleh skor 0.

\section{Simpulan}

Kesimpulan atas kinerja keuangan Koperasi kredit Sentosa Cukup Sehat dengan skor rata rata 67,35 selama 3 (tiga) tahun pertumbuhannya stabil dan tidak mengalami kenaikan yang signifikan dengan hasil penelitian sebagai berikut: 
1) Permodalan

Rasio modal sendiri tidak mengalami perubahan selama 3 tahun, dan perlu untuk mencapai ideal rasio 40-60\%. Pinjaman bermasalah terhadap total piutang selama tiga tahun masih tinggi dari tahun 2017, 2018 dan 2019 yaitu 22,88\%, 29,38 dan 27,21 idealnya dibawah $5 \%$, membutuhkan perhatian khusus. Cadangan risiko terhadap pinjaman bermasalah selama tiga tahun mengalami kenaikan dari tahun 2017,2018 dan 2019 yaitu 37,79\%, 24,09 dan 28,54 bila dibandingkan dengan pinjaman bermasalah rasionya masih rendah, minimal setara dengan pinjaman bermasalah.

2) Kualitas Aktiva Produktif

Pinjaman bermasalah terhadap total piutang selama tiga tahun masih tinggi dari tahun 2017, 2018 dan 2019 yaitu 22,88\%, 29,38 dan 27,21 idealnya dibawah 5\%, membutuhkan perhatian khusus. Cadangan risiko terhadap pinjaman bermasalah selama tiga tahun mengalami kenaikan dari tahun 2017,2018 dan 2019 yaitu 37,79\%, 24,09 dan 28,54 bila dibandingkan dengagn pinjaman bermasalah rasionya masih rendah, minimal setara dengan pinjaman bermasalah.

3) Manajemen

Pada aspek manajemen yang meliputi manajemen umum, kelembagaan, manajemen permodalan, manajemen aktiva, manajemen likuiditas. Berdasarkan analisa penulis baik dari data keuangan maupun melalui wawancara dengan pengurus dan manajemen Koperasi kredit Sentosa. Semua aspek tersebut sudah terpenuhi sesuai dengan data yang dibutuhkan.

4) Efisiensi

Pada penilaian efisiensi, salah satu indikator yang perlu diperhatikan yaitu Beban usaha terhadap SHU kotor idealnya $\leq 40 \%$ selama 3 tahun mengalami penurunan dari tahun 2017, 2018 dan 2019 yaitu 12,11\%, 3,44\% dan 5,25\% sekalipun tidak mempengaruhi skor. Beban usaha tersebut harus ditekan minimal $40 \%$ bila dibandingkan dengan SHU kotor.

5) Likuiditas

Pinjaman yang diberikan terhadap dana yang diterima idealnya $\leq 80-90 \%$ selama 3 tahun mengalami naik turun dari tahun 2017, 2018 dan 2019 yaitu 70,97\%, 67,99\% dan $68,44 \%$ skor mengalami kenaikan namun masih di bawah standar ideal.

6) Kemandirian dan Pertumbuhan

Rentabilitas aset selama tiga tahun mengalami perubahan dari tahun 2017, 2018 dan 2019 yaitu $0,07 \%, 0,17 \%$ dan $0,099 \%$. Ideal rasio rentabilitas aset diatas $10 \%(\geq 10 \%)$

Rentabilitas modal sendiri selama tiga tahun mengalami kenaikan dari tahun 2017, 2018 dan 2019 yaitu $0,07 \%, 1,36 \%$ dan 3,16\%. Ideal rasio rentabilitas modal sendiri diatas 5\% $(\geq 5 \%)$

7) Jati diri Koperasi

Promosi ekonomi anggota idealnya $\geq 10 \%$ selama 3 tahun memperoleh rasio minus (dibawah nol \%) maka selama tiga tahun memperoleh skor 0.

\section{Daftar Pustaka}

Undang - Undang Nomor 25 Tahun 1992 tentang Perkoperasian

Peraturan Deputi Bidang Kepengawasan Kementerian Koperasi Usaha Kecil dan Menengah Republik Indonesia Nomor 06/PER/Dep.6/IV/2016. Tentang Penilaian Kesehatan Koperasi Simpan Pinjam dan Usaha Simpan Pinjam.

Arikunto, S. (2010). Prosedur Penelitian Suatu Pendekatan Praktek. Jakarta: Rineka Cipta.

Ikatan. (2009). Standar Akuntansi Keuangan Entitas Tanpa Akuntabilitas Publik. Akuntansi Keuangan Ikatan Akuntan Indonesia: Jakarta.

Kusnadi, H. d. (2005). Ekonomi Koperasi. Jakarta: Fakultas Ekonomi, Universitas Indonesia. 
Limbong, B. (2010). PENGUSAHA KOPERASI, Memperkokoh Fondasi Ekonomi Rakyat. Jakarta: Margaretha Pustaka.

Moleong. (2014). Metodologi Penelitian Kualitatif . Bandung: PT Remaja Rosdakarya.

Ropke, J. (2012). Ekonomi Koperasi: Teori dan Manajemen. Yogyakarta: Graha Ilmu.

Soedjono, I. (2003). JATI DIRI KOPERASI. Jakarta: LSP2I.

Sugiyono. (2010). Metode Pendidikan Pendekatan Kuantitatif, Kualitatif dan R\&D. Bandung: Alfabeta.

Supardi. (2005). Metodologi Penelitian Ekonomi dan Bisnis. Yogyakarta: UII Press.

Supriyanto, A. (2017). Penilaian Kesehatan Koperasi. Palembang: Noer Fikri.

Widodo, T. (2010). Penilaian Kinerja. Salatiga: STIE AMA.

Widyawati, A. d. (2007). Dinamika Koperasi. Jakarta: Rineka Cipta.

\section{Copyright Disclaimer}

Copyright for this article is retained by the author(s), with first publication rights granted to the journal. 